\title{
PROJECT MANAGEMENT IMPLICATIONS ON CLIMATE CHANGE
}

\section{Bianca Georgiana OLARU}

The Bucharest University of Economic Studies, 6 Piata Romana, $1^{\text {st }}$ District, Bucharest, 010374, Romania e-mail: biancageorgiana.olaru@gmail.com

\begin{abstract}
At the moment, project management is a field in development and increasingly used in all economic sectors. Thus, we can specify that the project management plays a major role in order to consolidate a competitive advantage and achieve the organizational performance. In order to achieve long-term goals, it is necessary for the projects to consider several aspects, among which the mode and context of their implementation and the identification of the answers to the needs of the companies and organizations that implement the projects, as well as the follow-up of the measures / recommendations for solving certain problems. Further, in this article we will present the involvement of the project management, as well as funding sources in the field of climate change that may have major implications for agriculture.
\end{abstract}

KEYWORDS: project management, climate change, financial instruments, EU funds, cost-benefit analysis

\section{Introduction}

Climate change is a defining issue of our time, and we are at a defining moment, from changing weather patterns that threaten agricultural production to rising sea levels that increase the risk of flooding, the impact of climate change is global and has no broad precedent. Without taking action and identifying solutions at the moment, adapting to the impact of climate change will entail high costs and procedures will be more difficult. According to research in the field, the notion of project refers to the fact that it has a temporary character, since from the beginning of the project, that is, in the planning phase, the terms of development and scope are defined, as well as the resources established. The project manager and the members of his team within the project can play an essential role in meeting the proposed objectives and reaching the final result.

\section{General concepts concerning project management (PM) and project management office (PMO)}

Project management consists of planning, organizing and managing the tasks and resources that pursue a certain objective, under the conditions of time constraints, resources and costs. From this perspective, defining the objectives of the project acquires a major importance for according to these we establish the methods used. Looking at project management as a discipline it can be specified that it involves two different modes of management. One of the most common ways of using it is the management of the execution stages of a project, and the other is the project management from forecasting / planning until its completion. According to the PMBOK Guide on project management ( $4^{\text {th }}$ edition, 2008), the project management processes fall into five groups, namely: forecasting / planning, organizing, coordinating, training and controlling-evaluation.

Further, a figure representing the definition of the project is represented, as well as the processes and steps required to reach the final result.

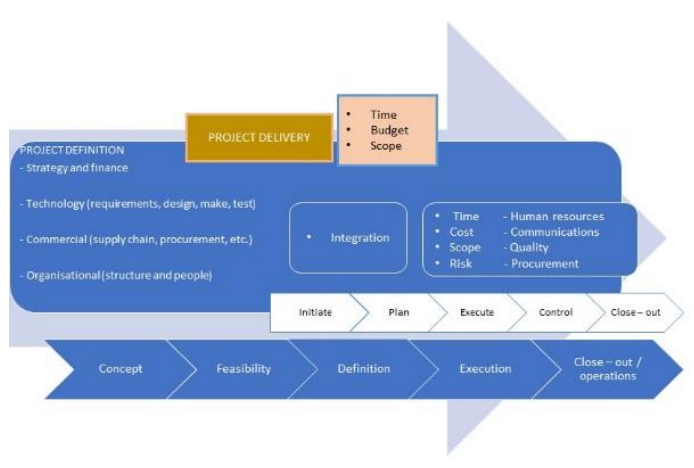

Fig. 1. Description of the steps in order to achieve the final result of a project 
PMO is a place where we consolidate all the knowledge, practices, experiences and resources of the project management in an organization / company.

In addition, the PMO has the role of identifying the best practices in a company / organization. Companies looking for greater efficiency and tighter project management are opening project management offices (PMOs).

The PMO has several tasks, including ensuring the implementation of procedures, practices and operations - on time, on budget and in the same way.

PMOs need to ensure the success of projects and programs and this is essential because organizations provide value through projects and programs.

\section{EU funds and financial instruments relating to climate change}

In order to efficiently implement strategies to adapt to climate change, investments are needed to support the application of strategies, policies and recommended measures.

In general, climate financing that is beneficial to the agricultural sector can be realized with the help of central and local public administration budgets, European, national, local funds, as well as the private sector, international development assistance, donor states and regional development banks.

At the same time, it should be mentioned that "many projects are being implemented in developing countries, the associated financial flows are a new and largely untapped source of income for the improvement of livelihoods" (Peskett et al., 2007).

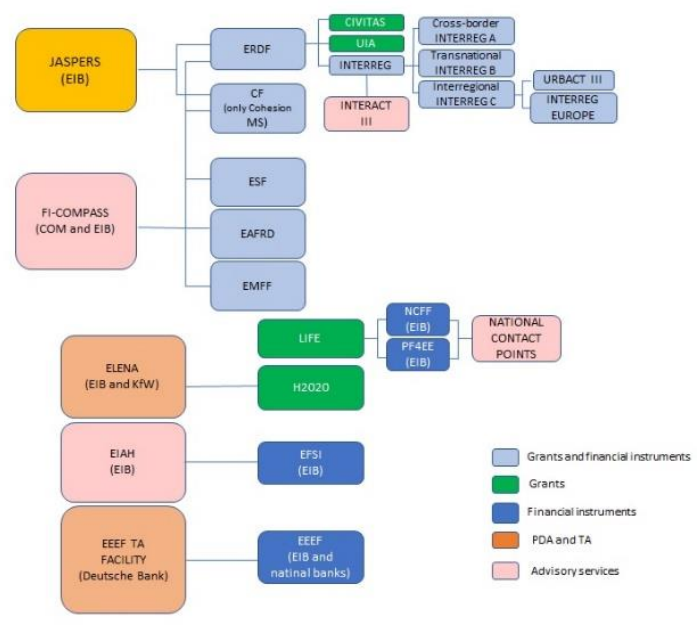

Fig. 2. Description of EU funding instruments available to local authorities

Climate finance is essential for both local and regional and national authorities because "investments can start in terms of reducing greenhouse gas emissions", as well as adaptation to climate change and can support additional private investments" (European Environment Agency, 2017). In order to recognize the needs of investments in the field of climate change, The EU has committed at least $20 \%$ of the budget of the European Union for the period 2014-2020. This budget results in several EU funds that can be made available to local authorities to finance actions / measures to reduce greenhouse gas emissions and to adapt to climate change. The financing available is represented in the form of non-reimbursable grants, financial instruments and financing available for assistance for project development (PDA) and technical assistance (TA), but also consultancy services available for specific EU financing instruments.

Source: Financing climate action: opportunities and challenges for local and regional authorities, Commission for the Environment, Climate Change and Energy, European Committee of the Regions (2017).

The above figure shows a brief description of the EU financing instruments available to local authorities to finance measures / actions to reduce greenhouse gas emissions, but also to adapt to climate change.

At the same time, it should be mentioned that those EU funding instruments that support the implementation of climate actions, but have a precise destination (companies, organizations or other institutions) are not part of the scope of the above presentation.

Further, will be present briefly some details regarding the financing programs of the projects in the field of climate change: ESIF (European structural and investment funds (ESIF) consists of providing a financing source in the field of climate change, reducing greenhouse gas emissions or adapting to climate change), (European Commission, 2017).

The ESIF family is composed of five distinct funds:

o ERDF (European Regional Development Fund);

o European Social Fund (ESF);

o Cohesion Fund (CF);

o European Agricultural Fund for Rural Development (EAFRD);

o European Maritime \& Fisheries Fund (EMFF).

The Managing Authority of each Member State that co-manages or implements projects / programs deals with the granting of grants or financial instruments for the final beneficiaries. Within the INTERREG program, URBACT III aims to support sustainable urban development integrated in the cities of Europe through an exchange of knowledge and 
better cooperation between Member States (URBACT, 2017).

The INTERACT III program wants to offer consultancy on various issues, but also how to use financial instruments within INTERREG. (INTERACT, 2017).

In addition, ERDF finances the CIVITAS program and the actions of urban innovation (UIA).

Civitas has the role to implement actions and measures regarding sustainable urban mobility in the EU.

The UIA aims to identify solutions and recommendations for urban challenges that range from the integration of migrants to the energy transition (Covenant of Mayors for Climate \& Energy, 2016).

JASPERS (Joint Assistance for Support Projects in European Regions) provides support to authorities and promoters in preparing and implementing ESIF projects (JASPERS, 2017).

FI-Compass is a consulting service made available to managing authorities.

In addition, ESIF includes integrated territorial systems, which allow managing authorities to correlate different priority axes and operational programs for financing integrated urban and territorial strategies.

In addition to ESIF there are other EU funds specific to the field of climate change: LIFE, HORIZONT 2020 (H2020), the European Fund for Strategic Investments and the European Fund for Energy Efficiency.

\section{The role of cost-benefit analysis}

The cost-benefit analysis consists of a process of evaluating the advantages and disadvantages of a project.

The economic analysis (cost-benefit) aims to evaluate the impact of the project on the well-being of the company / organization.

The main purpose of carrying out the economic analysis of an investment project is to provide information for the decision makers regarding the expected contribution of the project to the welfare of the company.

Thus, the analysis contributes to providing a means of identifying, quantifying and capitalizing on the types of impact that have emerged within a project. Also, if appropriate, the environmental impact will be established.

Cost benefit analysis "can be used to collect information on the consequence of a project, and to help organize the debate, by linking different opinions of various groups on what should be done to different opinions about the parameters of the analysis. CBA should therefore be understood as a complement and a tool to open consultations and discussions, not as a replacement for them." (Hallegatte, 2016).

The purpose of the economic analysis of the potential impact and investments in climate change is to identify, quantify and highlight both the possible impacts of climate change on the costs and benefits of the project, as well as possible measures that can contribute to reducing these effects.

Regarding the achievement of the analysis result, it will be relevant if climate resistance could be implemented, especially in situations where several technical options for climate resistance are available, and the most appropriate option for the effects resistance. climate change should be recommended to decision makers. Also, the economic analysis can contribute to indicating the most opportune moment of the investments of resistance to the effects of the climatic changes.

The cost-benefit analysis is done through some stages, and the most important are the identification and quantification of the potential impact of the project. The field of climate change may introduce a note of uncertainty in the economic analysis of a project, but uncertainty is not a novelty in economic analysis. The necessity of writing the scenarios was and is necessary, and the degree of fulfilment can be known if ex post analysis is performed.

\section{Identification of a management perspective in the field of climate change}

In terms of emergency management, extreme weather phenomena, unlike other "traditional" phenomena that occur in the short term, cause short and medium term disasters with an identifiable pattern or a predictable path that is easy to anticipate and follow, but also easy to respond to the immediate action and establishing well-defined procedures for returning to the initial situation.

At the same time, climate change must be treated as a moving phenomenon in the short and medium term. Climate change may be able to produce more prolonged events with high probability and major impact on agriculture or the economy. Currently, climate change is a threat that is difficult to manage by local or county authorities around the world.

In this regard, it is proposed to impose measures, strategies and plans to reduce greenhouse gas emissions and to adapt to climate change.

We cannot help but think that regardless of the measures we will take locally, nationally or internationally, there is a high probability that the effects of climate change will become the biggest challenges for human safety and well-being. 
Further, will be presented an emergency management perspective regarding climate change that has the role of providing a conceptual framework for stakeholders. The perspective will be able to be built around the management processes, such as forecasting and planning, coming to support the development of a guide for the elaboration of climate policies. In the forecasting stage (before planning), an assessment of the types of risks and vulnerabilities is required. It can be specified that these evaluations may be limited depending on the specific parameters. The assessments are conducted in a single jurisdiction and for a limited period of time (for example, 10 years). These parameters may be insufficient in terms of the impact of long-term climate change (50 or 100 years). At the same time, the risk assessment must also take into account the geographical characteristics, moving from a global perspective to a local one, as climate change acts, to a large extent, locally.

National and international entities must provide mechanisms for integrating local planners and their assessments into a global network and for connecting local planners and specific disaster threats that will vary from location to location, to a wider global nexus than climate change analysis and expertise.

In the field of climate change, the risk assessment process must correlate with the expertise of specialists, researchers, experts in international relations and other relevant persons who can add value in the evaluation.

The assessment of risks and vulnerabilities is followed by the forecasting / preparation and planning phases.

Preparation (forecasting) involves building capacity (technology and personnel), expertise (training) and resources to respond effectively in the interest of public safety and protection of community infrastructure in the face of the effects of climate change.

For example, sea level rise could flood lowlying areas of the globe, and populations living in those areas will have to migrate to other safe places.

An adverse event that leads to migration to other areas can cause long-term effects, affecting other generations.

Climate change has led to the loss of agricultural land, and the urgent need is to adapt agricultural crops (resilience to climate change).

To achieve a high degree of sustainability, each community must assess its environmental resources and risks, and then choose the level of risk they are willing to bear and define the losses that are unacceptable and those that must be avoided and ensure that all community development policies and activities comply with all requirements and recommendations. Given that the effects of climate change may be adverse, even devastating in some situations, it is necessary for all communities to be prepared for the management of situations in the event of the occurrence of events that can manifest in a very short time and cause major damage.

Some techniques for minimizing and reducing risk are already being widely used. At the same time, the authorities have adopted an inconsistent approach regarding the emergence of the risks caused by climate change that are occurring more and more regularly and unexpectedly.

In this regard, it should be specified that the decision makers should promote the correlation between the efforts to reduce or minimize the risk and the impact of climate change.

In most cases, responding to the effects of climate change and reducing them are considered two separate phases in managing emergency situations.

But, considering the time period of the global climate disaster already underway, the possibility of mitigating and creating communities more resistant to danger is, in fact, an appropriate response mechanism. This should provide a renewed impetus for reducing greenhouse gas emissions. It offers a double meaning for decision makers in order to highlight disaster reduction and resistance as a policy priority.

In fact, it should be a policy priority at local, national and international level.

In this respect, the decision-makers can contribute to the efficiency and management of climate change mitigation efforts and their response to them.

The main priority of the decision-makers must be the study and understanding of the potential impact of global climate change and the responsible improvement of mitigation and adaptation measures where necessary and feasible.

In this sense, a common approach or perspective in order to develop climate policies can help to achieve coherence and efficiency in the field of climate change.

\section{Recommendations}

With a view to a good management of financing in the field of climate change, the following steps can be recommended:

- allocation of additional resources to finance measures / actions to adapt to climate change and reduce greenhouse gas emissions;

In this way, central public authorities should continue to use financial sources and ensure that existing public investments function effectively.

Nationally, the existence of a financial fund for climate change can be highlighted, which will become an easier way of accessing the financing when needed, but also an easier attraction of the 
financing sources. All these will be able to contribute significantly to the realization of as many climatic actions. This financial fund should be managed by an existing institution, such as the Ministry of Finance / the Ministry of European Funds.

- implementation of economic and financial instruments in order to stimulate private sector investments in a green ecological economy, considering the extension of activities in front of financial constraints;

Central public authorities and the Government are largely dependent on subsidies to support climate development initiatives and a low carbon economy.

Obviously, it is clear that climate change will lead to a thorough preparation to prevent natural disasters and will require more resources globally, as well as the ability to combine or integrate efforts in jurisdictions and even internationally, when it is necessary to respond to disasters.

- evaluation of the impact of climate change in all sectors of activity;

- conducting studies to identify the risks and vulnerability of the danger in relation to the projected impact on climate change;

- identify and prioritize actions aimed at mitigating the risks and vulnerabilities identified to reduce the impact of climate change;

- increased protection and improvement of the environment and the role it plays in creating communities resistant to danger and reducing the impact of future disasters;

- improve response capabilities for all-natural disasters and expand resources to cope with the expected impacts of global climate change;

- support regional, national and international cooperation to assess risks and vulnerabilities and to respond to increasingly probable and unprecedented mega-disaster scenarios;

- identify progress and update climate change impact assessments.

\section{Conclusions}

Through this article is desired to increase the importance of climate finance and implement risk management for climate change. At the same time, a perspective has been suggested that may support decision-makers in assessing and responding to climate change.
Given that the planning, mitigation and response are best implemented within the community, decision makers need to adopt an emergency management perspective.

In conclusion, it can be mentioned that this article lays the foundations of an approach that will allow decision makers to interact and think about identifying measures that can be achieved through an analysis (for example, cost-benefit analysis) in the field of climate change. Climate change plays an important role and we must take into account the management of extreme weather events that can cause major damage, but also define it as a natural disaster in order to implement the preparation and planning of the best solutions to reduce gas emissions with greenhouse effect and adaptation to climate change.

\section{References}

[1]. ***, Quick reference guide on financing opportunities for local climate and energy actions (2014-2020), Covenant of Mayors for Climate \& Energy, 2016.

[2]. ***, European Environment Agency, 2017, Financing urban adaptation to climate change, EEA Report, no. 2/2017; and Ecofys and DIW Econ, 2016, How can EU climate financing be improved to achieve the 2030 climate and energy targets? Discussion paper, 9 May 2016.

[3]. ***, European Commission, European Structural and Investment Funds, viewed 1 August 2017, https://ec.europa.eu/info/funding-tenders/european-structural-andinvestment-funds_en).

[4]. Hallegatte S., Vogt-Schilb A. C., Bangalore M., Rozenberg J., Unbreakable: building the resilience of the poor in the face of natural disasters, Climate Change and Development series. Washington, D.C.: World Bank Group, 2016.

http://documents.worldbank.org/curated/en/512241480487839624/

Unbreakable-building-theresilience-of-the-poor-in-the-face-ofnatural-disasters.

[5]. ***, Interact, 2017, viewed 4 July 2017, http://www.interacteu.net/.

[6]. ***, Jaspers, 2017, viewed 4 July 2017, http://jaspers.eib.org/.

[7]. Peskett L., Luttrell C., Iwata M., Can standards for voluntary carbon offsets ensure development benefits?, Forest Briefing Paper, no. 13, Overseas Development Institute, London. www.odi.org.uk/resources/download/11.pdf, (2007).

[8]. ***, A Guide to the Project Management Book of Knowledge $(P M B O K), 4^{\text {th }}$ Edition, Project Management Institute, Newtown Square, PMI, 2008.

[9]. ***, URBACT, 2017, viewed 4 July 2017, http://urbact.eu/.

[10]. ***, Financing climate action: opportunities and challenges for local and regional authorities, Commission for the Environment, Climate Change and Energy, European Committee of the Regions, 2017. 